\title{
BMJ Open Improving cardiometabolic and mental health in women with gestational diabetes mellitus and their offspring: study protocol for MySweetHeart Trial, a randomised controlled trial
}

Antje Horsch, ${ }^{1,2}$ Leah Gilbert, ${ }^{3}$ Stefano Lanzi, ${ }^{3,4}$ Justine Gross, ${ }^{3}$ Bengt Kayser, ${ }^{5}$ Yvan Vial, ${ }^{1}$ Umberto Simeoni, ${ }^{6}$ Didier Hans, ${ }^{7}$ Alexandre Berney, ${ }^{8}$ Urte Scholz, ${ }^{9}$ Ruben Barakat, ${ }^{10}$ Jardena J Puder, ${ }^{2,11}$ on behalf of MySweetHeart Research Group

To cite: Horsch A, Gilbert L, Lanzi S, et al. Improving cardiometabolic and mental health in women with gestational diabetes mellitus and their offspring: study protocol for MySweetHeart Trial, a randomised controlled trial. BMJ Open 2018;8:e020462. doi:10.1136/ bmjopen-2017-020462

- Prepublication history for this paper is available online To view these files, please visit the journal online (http://dx.doi. org/10.1136/bmjopen-2017020462).

Received 6 November 2017 Accepted 10 November 2017

Check for updates

For numbered affiliations see end of article.

Correspondence to

Prof Antje Horsch;

antje.horsch@chuv.ch

\section{ABSTRACT}

Introduction Gestational diabetes mellitus (GDM) carries prenatal and perinatal risk for the mother and her offspring as well as longer-term risks for both the mother (obesity, diabetes, cardiovascular disease) and her child (obesity, type 2 diabetes). Compared with women without GDM, women with GDM are twice as likely to develop perinatal or postpartum depression. Lifestyle interventions for GDM are generally limited to physical activity and/or nutrition, often focus separately on the mother or the child and take place either during or after pregnancy, while their results are inconsistent. To increase efficacy of intervention, the multifactorial origins of GDM and the tight link between mental and metabolic as well as maternal and child health need to be heeded. This calls for an interdisciplinary transgenerational approach starting in, but continuing beyond pregnancy.

Methods and analysis This randomised controlled trial will assess the effect of a multidimensional interdisciplinary lifestyle and psychosocial intervention aimed at improving the metabolic and mental health of 200 women with GDM and their offspring. Women with GDM at 24-32 weeks gestational age who understand French or English, and their offspring and partners can participate. The intervention components will be delivered on top of usual care during pregnancy and the first year postpartum. Metabolic and mental health outcomes will be measured at 24-32 weeks of pregnancy, shortly after birth and at 6-8 weeks and 1 year after childbirth. Data will be analysed using intention-to-treat analyses. The MySweetHeart Trial is linked to the MySweetHeart Cohort (clinicaltrials.gov/ ct2/show/NCT02872974).

Ethics and dissemination We will disseminate the findings through regional, national and international conferences and through peer-reviewed journals. Trial registration number NCT02890693; Pre-results.

\section{INTRODUCTION}

Definition and prevalence of gestational diabetes mellitus (GDM)

GDM is characterised by glucose intolerance diagnosed during pregnancy not fulfilling the criteria for diabetes. ${ }^{12}$ It often resolves after
Strengths and limitations of this study

- The study will test the effects of a novel multidimensional interdisciplinary lifestyle and psychosocial intervention for women with gestational diabetes mellitus.

- The intervention focuses on both metabolic and mental health, of the mother and her offspring, which starts during pregnancy and continues beyond birth.

- The intervention draws on theories of health behaviour change through motivational and systemic approaches.

- Methodological rigour, including concealment of random allocation, blinded outcome assessors, regular monitoring and prospective trial registration and publication, should limit risk of bias.

- Unblinded participants and clinicians for some of the secondary outcomes may increase the risk of bias.

childbirth, ${ }^{12}$ although up to $40 \%$ of women have prediabetes in the early postpartum period. ${ }^{3}$ In Switzerland, the prevalence of GDM is $10.8 \%{ }^{4}$

\section{Morbidity of GDM and related conditions}

GDM carries prenatal and perinatal risk for the mother and her child and is also linked to postnatal risks. Long-term maternal risks include a 30\%-70\% GDM recurrence, a 7-fold higher 5-10year risk of type 2 diabetes and an increased risk of metabolic syndrome and cardiovascular disease. ${ }^{5-8}$ Compared with women without GDM, women with GDM are twice to four times ${ }^{9}$ as likely to develop antenatal or postpartum depression and approximately one-third of women with recent GDM develop postpartum depression. ${ }^{10}$ Postpartum depression leads to an increase in comfort eating and a decrease in physical 
activity ${ }^{11}$ thus putting the women at higher risk of weight gain and future diabetes. ${ }^{10}$

Regarding the child, the importance of the intrauterine and early postnatal environments for metabolic programming and modifications of the epigenome is increasingly recognised, ${ }^{12-14}$ particularly for metabolic diseases such as obesity and diabetes. ${ }^{15}$ Thus, GDM is related to macrosomia at birth $(>4 \mathrm{~kg})$, to excess body fat and (central) obesity and to insulin secretion in infants and children, the obesity being in part mediated by maternal body mass index (BMI) or birth weight. ${ }^{16-23}$ Intrauterine exposure to GDM also doubles the risk for subsequent type 2 diabetes in offspring compared with offspring of mothers with a high genetic predisposition for type 2 diabetes, but with normal glucose tolerance during the index pregnancy. ${ }^{24}$ Maternal prepregnancy overweight and excessive gestational weight gain also predict high birth weight and adiposity during infancy. ${ }^{125}$ This is highly relevant, as up to $60 \%-70 \%$ of women with GDM are overweight or obese before pregnancy. ${ }^{26}$ Finally, maternal lifestyle behaviour such as a high fat diet or lack of physical activity during pregnancy can influence offspring adiposity independent of maternal obesity. ${ }^{12} 27$

The higher risk for maternal postpartum depression is also associated with reduced parenting skills, which may have negative consequences for the development of the child. ${ }^{28-30}$ Parents of obese children may lack effective parenting skills providing both a consistent structured frame and emotional support. ${ }^{31}$ In women with GDM, psychosocial vulnerability including low levels of social and family networks is associated with more adverse neonatal outcomes, especially increased birth weight. ${ }^{32}$ Thus, there is a tight interaction between maternal lifestyle, weight status, mental health, social support as well as between maternal and child's overall health. In view of the high worldwide prevalence of (childhood) obesity and associated metabolic problems, this close link between maternal and child metabolic health and the resulting vicious cycle are very relevant. ${ }^{33} 34$ Because of the deleterious impact of GDM and lifestyle during pregnancy on the health of the mother and her offspring, it is crucial to intervene during the prenatal, perinatal and postnatal period.

\section{Modifiable risk factors of GDM}

Risk factors for GDM that are modifiable during pregnancy include excessive weight gain which is a very frequent phenomenon that is observed in a majority of pregnant women (in up to $75 \%$ of pregnancies). ${ }^{35} 36$ Further modifiable risk factors include lifestyle behaviours such as low levels of physical activity, high fat and animal protein consumption, high intake of added sugar and low intake of vegetable and fruit fiber. ${ }^{37}$ Regular food intake and avoidance of snacking can have beneficial effects on weight and glucose tolerance, but this has mostly been tested outside of pregnancy. ${ }^{38-42}$ Another key factor is mental health. Higher stress exposure and perceived stress during pregnancy have been linked to GDM and/or higher glucose levels in women. ${ }^{43-45}$ Psychological stress and negative life events can be associated with higher salivary cortisol levels during pregnancy, which might relate to higher glucose levels. ${ }^{46}$ Higher depression scores early in pregnancy also increase the risk for GDM. ${ }^{9}{ }^{47}$ On the other hand, social support has been shown to be protective regarding mental health and depression in particular. $^{9} 489$

Physical activity, nutrition and depression are interlinked. Physical activity can reduce symptoms of depression, ${ }^{50}$ and there is a two-directional relationship between unhealthy eating and the incidence of symptoms of depression. ${ }^{51}$ Mindfulness and mindful eating can have a beneficial impact on weight loss and food cravings. ${ }^{52-54}$

\section{Prior studies having evaluated lifestyle interventions in GDM}

Most interventions in GDM focus either on dietary or on physical activity changes and only last during pregnancy.

Dietary advice is recommended for all women with GDM to improve glycaemic control and to provide adequate nutrition. ${ }^{1}$ Of the few existing trials, the majority focused on either low carbohydrate or low glycaemic index foods. Results were not consistent and effect sizes were small, but low glycaemic diets, sometimes in combination of higher fibre intake, were found to have a favourable impact on insulin requirements, birth weight and/or maternal weight gain. ${ }^{55-57} \mathrm{~A}$ recent Cochrane review found that more evidence is needed to assess the effects of different types of dietary advice to give to women with GDM. ${ }^{58}$ As fat, especially saturated fat, is a risk factor for both GDM and type 2 diabetes, decreasing animal fat intake represents an interesting novel approach. ${ }^{59-62}$ Indeed, a high-complex carbohydrate/low-fat diet improved glycaemic values and insulin resistance in women with GDM as well as infant adiposity in a pilot study of women with GDM. ${ }^{63}$ Regarding eating behaviour, a recent intervention focusing on mindfulness-based eating awareness that aimed at increasing awareness of inner cues, such as hunger and satiety, at identification of emotional eating and eating triggers, had a beneficial impact on glycaemic control. $^{6465}$

Although recommended for GDM treatment, guidelines do not specify the type of physical activity or its timing in regards to meal intake. ${ }^{667}$ Aerobic and resistance exercise can be accomplished during pregnancy in the absence of contraindications, ${ }^{68}$ but motivation, compliance, perceived health and lack of time appear to be major limiting factors. ${ }^{4869}$ A recent review concluded that physical activity, both aerobic and resistance exercise, may improve glycaemic control and/or limit insulin use in women with GDM. ${ }^{70}$ Regular physical activity can also limit pregnancy weight gain, stabilise maternal mood and reduce fetal fat mass (FM) and physiological stress responses in the offspring. ${ }^{276971}$

To our knowledge, there are no evidence-based psychological interventions for women with GDM and no international guidelines for psychosocial management exist, ${ }^{72}$ although evidence shows that inclusion of partners can be helpful. ${ }^{774}$ 


\section{Postpartum follow-up and interventions}

Due to the increased risk of development or persistence of prediabetes and diabetes, management of women with GDM in the postpartum period is essential. The American Diabetes Association, the American College of Obstetricians and Gynaecologists and the National Diabetes Education Program recommend testing within 4-12 weeks postpartum with a 2 hour $75 \mathrm{~g}$ oral glucose tolerance test (oGTT). ${ }^{275} 76$

Weightloss is an important predictor to prevent diabetes in this high-risk population. Thus, in the Diabetes Prevention Program, weight loss after GDM reduced future diabetes incidence by $16 \%$ for every kilogram lost. ${ }^{77}$ The Nurses Health Study found that healthy diet patterns such as a Mediterranean diet, a Dietary approaches to stop hypertension (DASH) pattern diet or an Alternative Healthy Eating diet reduced diabetes incidence by $40 \%-57 \%$ in women who had GDM 14 years before. ${ }^{78}$ Evidence of the Gestational Diabetes' Effects on Moms study shows that a lifestyle intervention that starts during pregnancy and continues postpartum is feasible and may prevent pregnancy weight retention and help overweight women lose weight. ${ }^{79} 80$

In the postpartum period after GDM, low social support was related to low adherence to a healthy lifestyle, thus contributing to an increased risk of type 2 diabetes. ${ }^{81}$ In another study, social support was a key factor for the adoption of physical activity among women after GDM. ${ }^{82}$ Finally, integrating partners into the intervention helped to maximise participation in an intervention that aimed to prevent type 2 diabetes after GDM. ${ }^{74}$

\section{Prevention strategies for the child}

Offspring of women with GDM are at higher risk for childhood obesity ${ }^{83}$ and intervening in the early postpartum period is therefore essential. Several modifiable risk or protective factors have been identified, such as infant feeding mode (bottle vs breastfeeding), parental responsiveness to infant feeding cues and infant distress, the age of bottle weaning, timing of the introduction of solid food, sweetened beverage consumption and lack of physical activity. ${ }^{84-88}$ Inactivity can delay motor development and further increases the risk for early childhood obesity. ${ }^{85}$ 89-91

Parenting skills interventions that focus on these factors provide anticipatory guidance and teach parents how to identify and respond appropriately to infant cues and distress to positively influence self-regulatory capacities, well-being and the developing control of the infant's food intake in order to avoid eating in the absence of hunger have shown beneficial results. ${ }^{84} 859293$

\section{Theoretical framework for behaviour change interventions}

The chosen theoretical framework for the behaviour change interventions is the Health Action Process Approach (HAPA). ${ }^{94}$

The HAPA distinguishes between a motivational and a volitional phase of behavioural change. In the motivational phase, the process of forming an intention to engage in a health behaviour takes place. Being aware of a personal risk due to the unhealthy behaviour, perceiving more benefits than disadvantages of changing the behaviour (outcome expectancies) and believing in one's own abilities to change the behaviour (self-efficacy) are the factors that the HAPA specifies to increase the likelihood of a behavioural intention to change the behaviour. After an intention has been set, the individual enters the volitional phase. Here, action control, action planning, coping planning and again self-efficacy are assumed to be crucial for translating the intention into behaviour. Action control and its components (ie, the awareness of one's own standards for the new behaviour, self-monitoring and regulatory effort in case of a discrepancy between the intended and the actual behaviour) have been demonstrated in several populations and across several behaviours, among them physical activity and diet, to be effective in promoting behavioural change. ${ }^{95}$ Moreover, action planning and coping planning are crucial postintentional variables in the HAPA. Action planning, which is also known as implementation intentions, ${ }^{9697}$ refers to if-then plans regarding the exact planning of when, where and how a behaviour will be implemented. Implementation intentions have been demonstrated to be an effective tool of behavioural change in numerous settings and behaviours, displaying medium to strong effect sizes ${ }^{98-100}$ Coping plans refer to plans that specify a critical barrier to the intended/ planned behaviour and a specific strategy on how to cope with this barrier. ${ }^{101}$ A recent systematic review attests that the combination of action planning and coping planning seems to be most effective for behavioural change. ${ }^{102}$ Self-efficacy has also been shown to be a crucial factor in health behaviour change across different behaviours and different populations.

\section{Development of a complex multidimensional interdisciplinary lifestyle intervention}

Given that single risk factor interventions have shown limited efficacy, and considering the multifactorial origins of GDM, complex interdisciplinary approaches that start in pregnancy and continue postpartum, targeting both the mother and the child could be more efficient. This is especially important with regard to the intergenerational transmission of risk. ${ }^{103}$ Some authors specifically called for the need to integrate psychological support in a lifestyle intervention. ${ }^{104}$ Typical characteristics of complex interventions are that they contain several interacting components, their high number of outcomes and that a high degree of flexibility or tailoring of the intervention is permitted. ${ }^{105}$ Furthermore, complex interventions work best if tailored to local circumstances rather than completely standardised. ${ }^{105}$

\section{Aims}

This study aims to test the effect of an evidence-based, complex interdisciplinary lifestyle and psychosocial continuous prepartum and postpartum intervention in women with GDM on maternal and offspring metabolic 


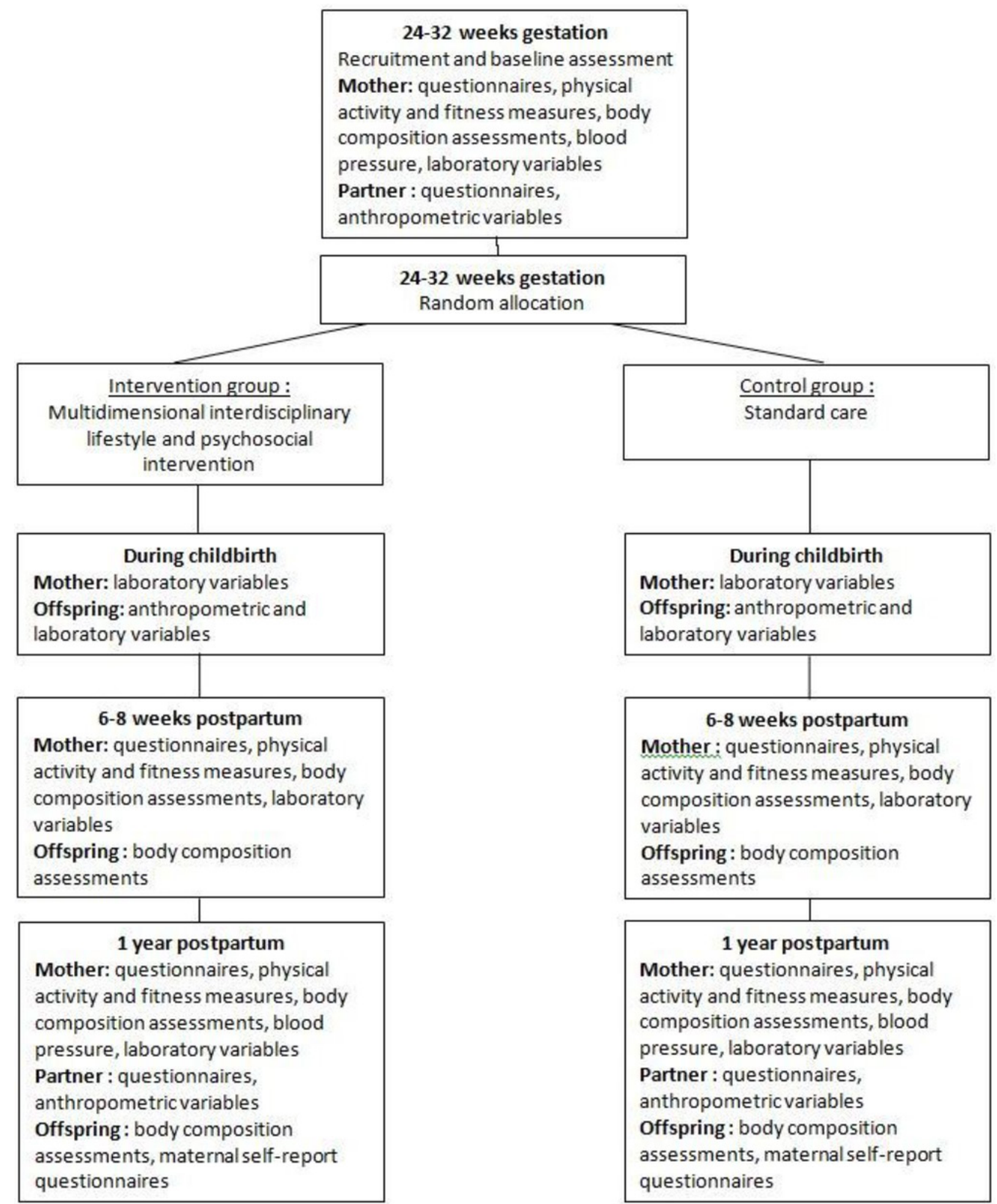

Figure 1 Trial flowchart.

and mental health outcomes up to 1 year postpartum. It also aims to investigate longitudinal associations, thus increasing the understanding of the development of maternal and child obesity, glucose intolerance and mental health problems.

\section{METHODS}

\section{Study design}

We will conduct a monocentric superiority open Randomised Controlled Trial (RCT) with minimal risk aiming to test the effect of a multidimensional interdisciplinary lifestyle and psychosocial intervention for pregnant women with GDM and their offspring, compared with treatment-as-usual (figure 1).
Study population, recruitment, group allocation and blinding Women diagnosed with GDM according to IADPSG criteria ${ }^{106107}$ will be recruited (1) in our diabetes and pregnancy clinic, where patients both from the University Hospital Vaud (CHUV) antenatal care clinic and from obstetricians in private practice are referred to or (2) referred to our clinic for the study from diabetologists in private practice and from regional hospitals in the canton Vaud. Following their first clinical appointment, the study coordinator will explain the study and give the information sheet to the patient. Participating women will receive for their time, effort as well as the fees for their frequent travels CHF 250 at the $6-8$ week postpartum visit and then CHF 200 at the 1 year visit. 
The inclusion criteria are as follows: pregnant women aged $\geq 18$ years, with GDM at 24-32 weeks of gestation and understanding French or English. Women on strict bed-rest, with pre-existing DM or current episode of severe mental disorder will be excluded.

The allocation ratio of randomisation is $1: 1$, using the block randomisation method (blocks of 4) after stratification for the place of the usual care (at the CHUV or the respective private diabetologist/regional hospital). Thus, each referral centre represents its own control. However, all intervention components and all the evaluations take place at the CHUV hospital. For allocation of the participants, a computer-generated list of random blocks is used (https://www.sealedenvelope.com/simple-randomiser). The allocation sequence will be concealed from the research staff assessing the primary outcomes in sequentially numbered, opaque, sealed envelopes. Envelopes will be opened only after the enrolled participants gave signed consent and completed all baseline assessments. Assessors of primary outcomes and the statistician will be blind to group allocation.

\section{Control group}

The control group will receive treatment-as-usual, which is based on the current guidelines of the American Diabetes Association $^{2}$ and of the Endocrine Society. ${ }^{1}$ Patients are first seen at 24-32 weeks of gestation by a physician and/ or a specialised nurse practitioner who will then provide follow-up until childbirth. During the first visit, patients learn about GDM and how to perform self-control of blood glucose 4 times a day (fasting and 2 hours postprandially). ${ }^{108}$

Regarding the weight, lifestyle and mental health goals, details are provided in tables $1 \mathrm{~A}$ and B. Standard advice about gestational weight gain according to the Institute of Medicine recommendations ${ }^{109} 110$ will be given. Patients have one appointment with a registered dietician in order to receive individualised dietary advice, with a focus on how to distribute carbohydrate intake over several meals and snacks, limit the intake of free sugars to less than $10 \%$, and increase fibre intake to up to $30 \mathrm{~g}$ per day. Patients are encouraged to increase physical activity according to the Endocrine Society Guidelines. ${ }^{1}$ If despite lifestyle measures, glucose values remain above targets, ${ }^{12}$ twice or more during a 2-week period, ${ }^{108}$ metformin or insulin treatment is installed depending on glucose values (eg, insulin in case of relatively high glycaemic values) and patient preference. ${ }^{111}$

In the postpartum period, patients then undergo a $75 \mathrm{~g}$ oGTT at 6-8 weeks postpartum and are seen afterwards by the physician and a dietician jointly to discuss results and further management and provide general advice on lifestyle measures. ${ }^{12}$ Patients then resume usual care by their healthcare provider outside of the clinic.

The frequency of blood glucose self-control, the thresholds for initiating treatment, the choice of the medical treatment and the first visit with the dietician will be the same in the control and in the intervention group.

\section{Intervention group}

The complex, multidimensional, interdisciplinary lifestyle and psychosocial intervention will be offered on top of usual care. Details for the goals of the intervention group are provided in tables $1 \mathrm{~A}$ and B. All goals will be individually tailored and set by the respective experts (dietician and physiotherapist) during the face-to-face prepartum consultations, based on the patients' context and capacities $^{112}$ and transmitted to the coach (see below). The goals will also be discussed during bimonthly interdisciplinary meetings in the postpartum period and exchanges regarding further adaptations. ${ }^{83-86}$ 89-93 113-124

Counselling about gestational weight gain according to the Institute of Medicine recommendations and about weight retention will be given. ${ }^{109} 110$ In addition to the dietary goals set in the control group, the intervention aims to reduce intake of total lipid intake, ${ }^{125}$ saturated fat, ${ }^{126}$ to prioritise higher quality fats such as monounsaturated fat present in the Mediterranean, ${ }^{127} 128$ DASH and plant-based diets and to reduce red or processed meat intake. ${ }^{127}$ It also aims to encourage mindful eating ${ }^{129-131}$ and regular, structured eating. ${ }^{1}$ The intervention also includes the promotion of continuous breastfeeding for at least 6 months. The intervention encourages aerobic and resistance physical activity ${ }^{66} 68132133$ and aims to reduce sedentary behaviour. ${ }^{134}$

Regarding the psychosocial part, ${ }^{135}$ patients will be screened for depression at study beginning, at 6-8 weeks, at 7 months postpartum and at 1 year postpartum. According to a stepped care approach (based on the patient's Edinburgh Postnatal Depression Scale (EPDS) score), facilitated self-help with the coach or individual cognitive behavioural therapy sessions with the clinical psychologist will be offered. ${ }^{135}$ Common elements are: (1) challenge most unhelpful negative cognitions, (2) schedule at least one pleasurable activity per day, (3) increase social contacts, (4) improve sleep routine, (5) identify most stressful situations and apply cognitive behavioural strategies to improve their management. ${ }^{135} 136$ Patients who require a psychiatric evaluation will be referred to a psychiatry liaison service. Treatment goals for the offspring focus on diet, breastfeeding, nutrition, physical activity ${ }^{137}$ and emotional regulation, all of which will be addressed via psychoeducation and parenting training (see tables $1 \mathrm{~A}$ and $\mathrm{B}$ ).

The intervention will take place during pregnancy and during the first year postpartum and will be delivered in individual sessions during the prepartum period with members of the multidisciplinary team, in 3-4 monthly individual interdisciplinary sessions in the postpartum period covering both the mother and the child or during group workshops. Throughout the pregnancy and up to 1 year postpartum, patients will be accompanied and supported by a lifestyle coach (with regular supervision by a clinical psychologist) who will monitor adherence to the intervention, provide booster messages, identify barriers and facilitators, discuss action plans, provide support and teach strategies to work towards the individual goals. The 


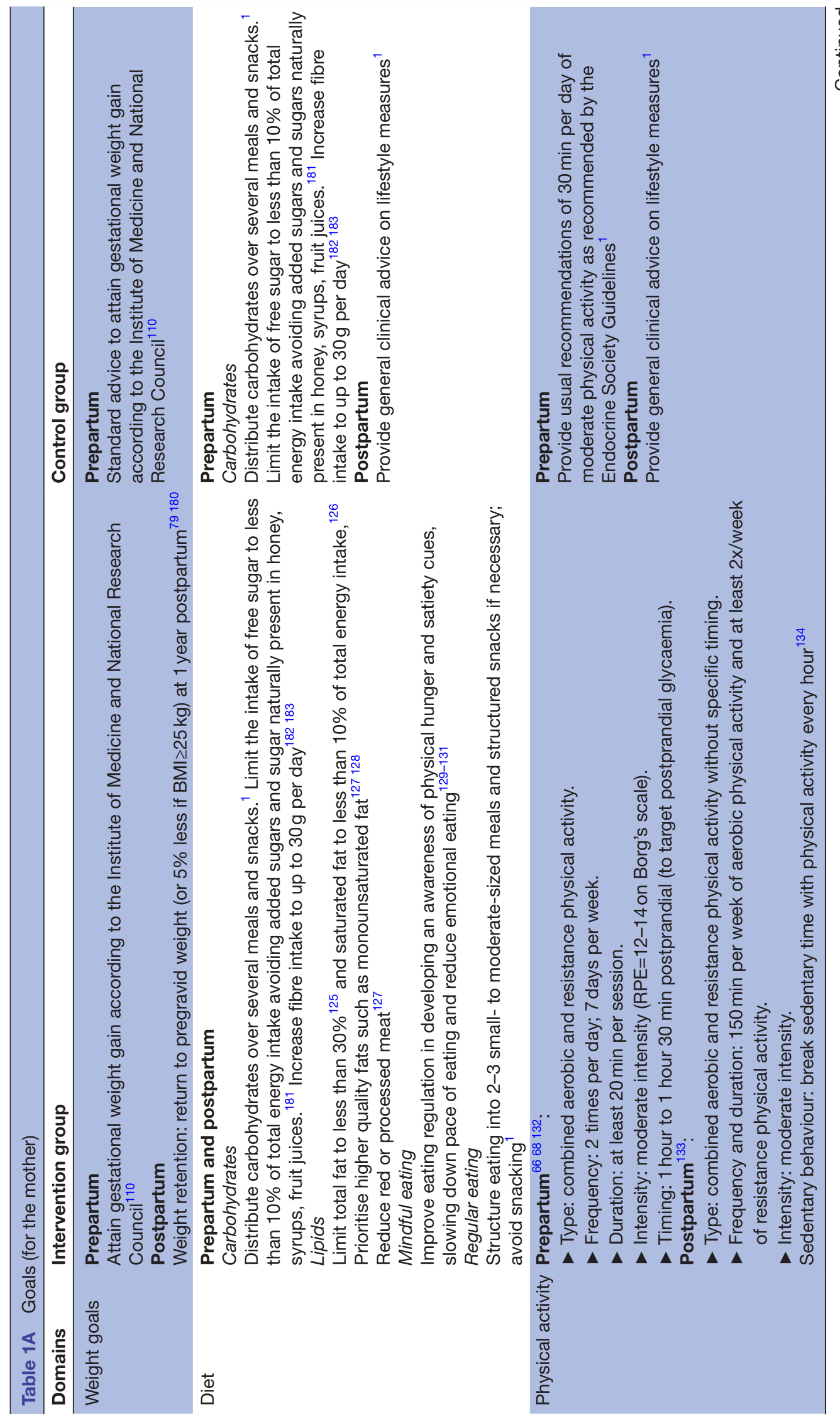




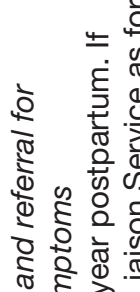

की के 줄

ब.

离

के के के

के $\frac{1}{0}$ 西

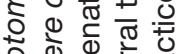

है

ह

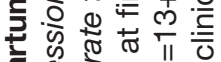

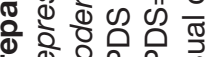

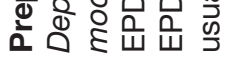

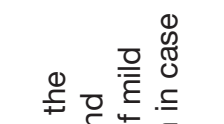

$\stackrel{\oplus}{5}$

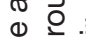

ง ธ ธ

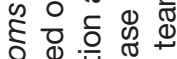

年

원도

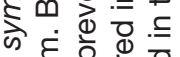

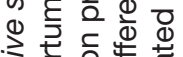

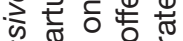

(1) 은 으으 잉

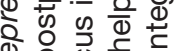

d 으은 든

¿ ঠั

స ญ 凹 ๘

히도웡

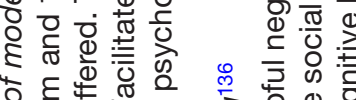

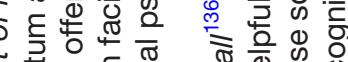

䒕 凹 ᄃ

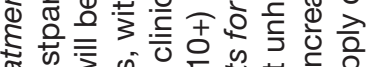

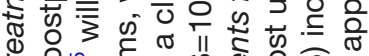

Ð

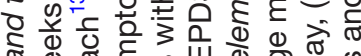

ब

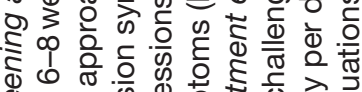

$\varepsilon \stackrel{0}{0}$

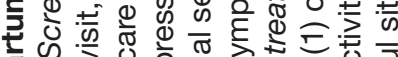
बक 율

은

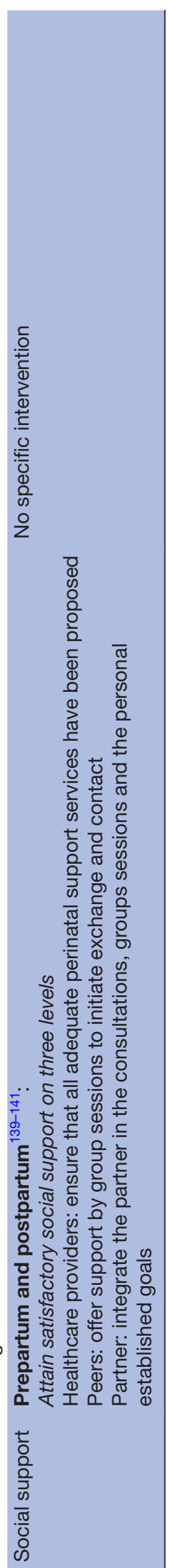

Table 1B Goals for the infant up to 1 year (targeted through parent education)

\begin{tabular}{|c|c|c|}
\hline Domains & Intervention group & Control group \\
\hline Diet & $\begin{array}{l}\text { Breastfeeding: encourage } \\
\text { continuation for at least } \\
6 \text { months }^{184} \\
\text { Soothing: propose alternative } \\
\text { methods than feeding } \\
\text { Hunger and satiety: recognise the } \\
\text { respective cues } \\
\text { Food: introduce solid food after at } \\
\text { least 4-6 months of age }\end{array}$ & $\begin{array}{l}\text { Provide general } \\
\text { recommendation } \\
\text { for breastfeeding }\end{array}$ \\
\hline $\begin{array}{l}\text { Physical } \\
\text { activity }\end{array}$ & $\begin{array}{l}\text { Physical activity: encourage } \\
\text { physical activity during waking } \\
\text { hours, reaching } 180 \mathrm{~min} / \text { day at } \\
1 \text { year of age }{ }^{137} \\
\text { Sedentary behaviour: no screen } \\
\text { time }^{137}\end{array}$ & $\begin{array}{l}\text { No specific } \\
\text { intervention }\end{array}$ \\
\hline $\begin{array}{l}\text { Mental } \\
\text { health }\end{array}$ & $\begin{array}{l}\text { Parental regulation of infant } \\
\text { distress and self regulation } \\
\text { capacity: increased through } \\
\text { parent education during prenatal } \\
\text { and postnatal workshops and } \\
\text { postpartum interdisciplinary } \\
\text { sessions and reinforced by } \\
\text { coach }^{85} 92\end{array}$ & $\begin{array}{l}\text { No specific } \\
\text { intervention }\end{array}$ \\
\hline
\end{tabular}

BMI, body mass index; EPDS, Edinburgh Postnatal Depression Scale; RPE, rate of perceived exertion.

coach will offer different behaviour change techniques ${ }^{138}$ targeting the $\mathrm{HAPA}^{90}$ constructs relevant for the respective phase participants are in. Depending on the needs and the progress of participants, the content of the theory-based interventions will be tailored to the individuals. Self-monitoring by the patient will help to clarify the situation and adjust the goals. During pregnancy, the coach will have approximately 15 min of biweekly contact (by phone, videophone and/or face to face after clinical visits). During the first year postpartum, the coach will have phone/videophone contact with the mother every 3 weeks until 6 months and then monthly. Patients will receive a folder with written materials and resources and worksheets or text messages (according to preferences) to monitor their personalised tailored goals and action plans in the different domains throughout the study period. Close collaboration with paediatricians, obstetricians and existing healthcare networks that form part of the patients' usual clinical care will be ensured.

Social support will be encouraged on three levels. ${ }^{139-141}$ First, partners will be invited to attend individual and group sessions during both the prepartum and postpartum period. If partners are unable to attend those sessions, a phone/videophone contact at the end of the sessions will be offered. Second, small peer support groups will be formed during the prepartum and postpartum workshops. Third, the coach will also transmit information about other local support offers and will refer the patient to a lactation consultant, if desired by the patient. There are no specific other intervention parts 
for the partners except their integration in the maternal and offspring goals, which include a family approach.

\section{Primary outcomes}

The primary outcomes are differences between the intervention and the control groups in (1) the decrease in maternal weight (calibrated Seca scale) between 24-32 weeks gestational age (GA) and 1 year postpartum and (2) attenuation in maternal symptoms of depression (EPDS) during the same time period.

\section{Secondary outcomes}

Maternal outcomes

The following lifestyle behaviours will be measured: carbohydrate and fat intake (Food Frequency Questionnaire (FFQ), see below), eating behaviour (French Intuitive Eating Scale (IES), see below), breastfeeding (self-report), physical activity (accelerometer GENEActiv), sleep (Pittsburgh Sleep Quality Index (PSQI), see below). Aerobic fitness will be estimated using the Chester step test (see below) and muscular fitness will be assessed with the hand grip strength using a Jamar dynamometer (see below). Body composition measures include bioelectrical impedance analysis (BIA), the sum of four skinfolds (Harpenden callipers) as well as Dual-Energy-X-ray absorptiometry (iDXA device, GEHC-Lunar, Madison, Wisconsin, USA). Cardiometabolic laboratory variables and miRNA will be measured (for more details, see Di Bernardo et $a l^{142}$ ).

Additional mental health indicators include anxiety (Anxiety subscale of the Hospital Anxiety and Depression Scale (HADS), see below), depression (EPDS and Whooley questions, see below), well-being (WHO Well-Being Index, see below), social support (Medical Outcomes Study Social Support Survey-short form (mMOS-SS), see below) and parenting stress (Parenting Stress Scale-short form (PSI-SF), see below).

\section{Offspring outcomes}

Cardiometabolic laboratory variables and miRNA will be measured in the cord blood (for more details, see Di Bernardo et $_{\text {al }}{ }^{142}$ ).

Body composition measures include height, weight (standardised tools for infants), BIA and the sum of four skinfolds (Harpenden callipers).

Mental health indicators include self-regulation (Difficult Child subscale of the Parenting Stress Index-Short form, see below) and sleep (Brief Infant Sleep Questionnaire (BISQ), see below).

\section{Data collection and visits}

The study started in September 2016. The participation in the study is voluntary and involves a sequence of events and measurements as summarised in table 2 .

At 24-32 weeks GA, baseline assessments are carried out (visit 1), including the validated questionnaires, physical activity and fitness measures, body composition assessments and laboratory variables. If the women agree, their partners are also informed about the study and invited to participate using a separate information sheet and consent form. Once they have signed a separate consent form, research staff will measure the partner's weight and height and ask him to complete validated self-report questionnaires (table 2).

During childbirth (visit 2), maternal blood will be drawn at the entry into the delivery room. After childbirth, blood will be drawn from the cord following clamping and birth weight will be recorded. Offspring birth weight and height will be collected from the hospital birth record.

At 6-8 weeks postpartum (visit 3), while attending a clinical appointment, women will be asked to complete a series of validated self-report questionnaires online, and physical activity and fitness measures, body composition assessments and laboratory variables will be measured. They will undergo a $75 \mathrm{~g}$ oGTT with blood sampling. Body composition assessments of their offspring will be assessed.

At 1 year postpartum (final visit, visit 4), participants will be asked to complete a series of validated self-report questionnaires online, and physical activity, aerobic and muscular fitness, body composition and laboratory variables will be measured. Women, who sign an additional consent, will also undergo Bone Densitometry (DEXA) measures for more detailed body composition. They will undergo a $75 \mathrm{~g}$ oGTT with blood sampling and blood pressure (three measures) will be measured. Body composition measures of their offspring will again be assessed.

\section{Partners}

Partners of participating women who also agree to participate will be asked to complete validated questionnaires and body composition assessments at study entry and study end (when the women are at 24-32 weeks GA and at 1 year postpartum, respectively).

\section{Measures}

All measures and their timings are listed in detail in table 2.

\section{Self-report questionnaires: mother and partner}

Symptoms of depression in the preceding 7 days are assessed with EPDS, ${ }^{143}$ which has been validated for pregnant women. ${ }^{144}$ Each item is scored on a 4-point scale, the minimum and maximum total scores being 0 and 30 , respectively. The EPDS has been validated in a French sample and good psychometric properties have been reported. ${ }^{145}$ The original authors suggested a cut-off score of 12.5 as an indication of clinically significant depression but others reported that a score of 10 was the most useful cut-off in a French sample of postnatal women. ${ }^{145}$

Exposure to life events is measured with the Life Events Questionnaire (see below), in which participants are given a list of three negative pregnancy-related major events (suspected growth retardation, vaginal bleeding, premature contractions) as well as 10 negative pregnancy-unrelated major life events (death of someone they were close to, serious illness, exposure to abuse, exposure to violence, 







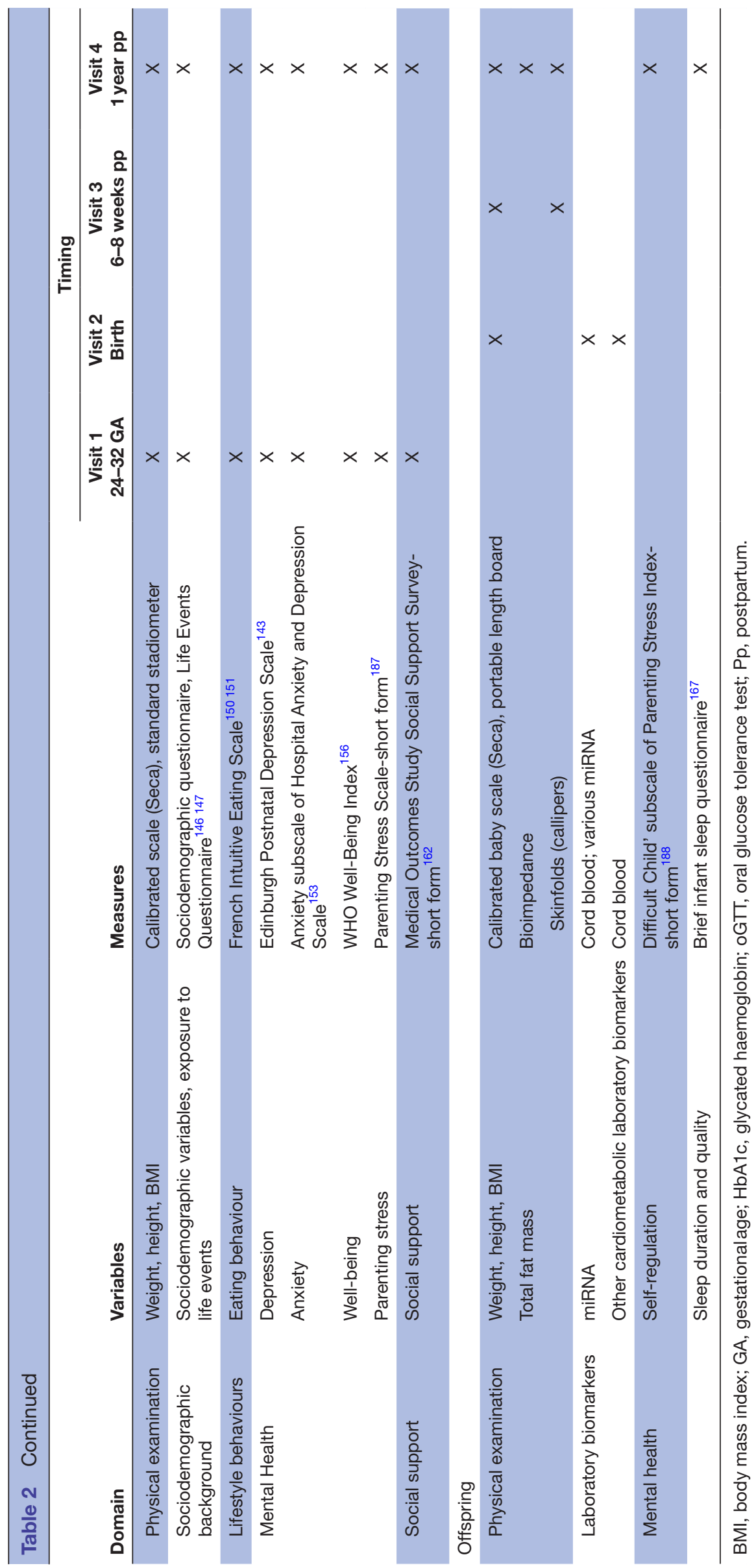


serious accident, unemployment, disability, alcohol/drug abuse, divorce, moving house) and have to indicate whether they have been exposed to any of these events in the last 12 months. ${ }^{146147}$

Carbohydrate and fat intake is assessed with the FFQ. ${ }^{148} 149$ The FFQ comprises 97 items listing different types of food and drinks (tea, butter, tomatoes, chicken and so on) and six available spaces which allow the person to write any additional food or drinks she/he might have taken over a 4-week period. Each item is rated for frequency of use on a 6-point Likert scale ranging from 1 'never in the past 4 weeks' to 6 'twice a day'. The items are also rated on a quantity scale which allows the person to compare the portion they took in comparison with a reference portion (ie, $150 \mathrm{~g}$, one piece and so on) with three response choices: 'less', 'same' or 'more'.

Eating behaviour is measured with the French IES, ${ }^{150} 151$ assessing an individuals' tendency to follow their physical hunger and satiety cues when determining when, what and how much to eat. ${ }^{152}$ In the current study, the IES was modified by taking out the unconditional permission to eat scale, as women with GDM are given strict diet counselling. Women respond using a 5-point Likert scale ranging from 1 'strongly disagree' to 5 'strongly agree'. To calculate the scale scores, negative items are reversed, so that high scores on the total measure and subscales indicate greater intuitive eating. The individual scores of items under each subscale are then summed to obtain subscale scores ranging from 1 to 5. The French version of the IES-2 demonstrated good psychometric properties. ${ }^{151}$

Anxiety symptoms are assessed with the HADS, ${ }^{153-155}$ which has seven items measuring state-anxiety in the last 7 days. Each item is scored from 0 to 3, with higher scores indicating greater anxiety. Scores from 8 to 10 indicate possible clinical disorder and scores between 11 and 21 indicate probable clinical disorder. Furthermore, it may be used as a measure of symptom severity from normal $(0-7)$, mild (8-10), moderate (11-14), to severe (15-21). The HADS has good psychometric properties. ${ }^{154}$

Well-being is measured with the WHO Well-Being Index (WHO-5), ${ }^{156}$ which consists of 5 questions assessing the subjective well-being of the respondents. The items are measured on a 5-point Likert scale ranging from 0 'at no time' to 5 'all of the time'. The scale has adequate validity both as a screening tool for depression and as an outcome measure in clinical trials and has been applied successfully across a wide range of study fields. The scale has been used most extensively in endocrinology ${ }^{156}$ and has good psychometric properties in French. ${ }^{157}$

Parenting stress is assessed with the PSI-SF. ${ }^{158}$ It has 36 items and consists of three subscales that assess parental distress, dysfunctional parent-child interactions and child difficulties. Items are rated using a 5-point Likert scale from 1 'totally agree' to 5 'totally disagree'. The PSI has good psychometric properties. ${ }^{159}$

Sleep duration and quality are measured with the PSQI ${ }^{160}$ which has 19 items and measures retrospective sleep quality and disturbances over a 1-month period. It discriminates between good and poor sleepers and provides a brief, clinically useful assessment of multiple sleep disturbances. The 19 items are grouped into seven equally weighted component scores: Subjective Sleep Quality, Sleep Latency, Sleep Duration, Habitual Sleep Efficiency, Sleep Disturbances, Use of Sleeping Medication and Daytime Dysfunction. Items 1-4 are free entry of: usual bed and wake times, minutes of total sleep time and sleep latency (minutes). Items 5-18 are rated on a 4-point Likert scale responses pertaining to problem frequency: ranging from 0 ' $n o t$ during the past month' to 3 'three or more times a week'. Item 19 is rated on a 4-point Likert scale rating of overall sleep quality ranging from 0 'very good' to 3 'very bad.' All component scores range from 0 to 3. The Global Score ranges from 0 to 21 , with a higher score indicating poorer sleep quality and a cut-off score of $>5$ distinguishing poor sleepers from good sleepers. The questionnaire is validated in French. ${ }^{160}$ The English questionnaire was retrieved directly from the author. $^{161}$

Social support is measured with the mMOS-SS, ${ }^{162}$ which has two subscales assessing emotional and instrumental social support composed of four items to identify potentially modifiable social support deficits. It has good psychometric properties ${ }^{162}$ and was translated into French. ${ }^{163}$

Food to soothe is assessed with the Food to Soothe Questionnaire ${ }^{87}$ the first subscale of the Baby's Basic Needs Questionnaire. ${ }^{87}$ It measures parents' likeliness to use food to soothe their child by 33 items with a Likert scale ranging from 1 to 5 . Twenty-six items present scenarios in which parents might use food to soothe. Seven items measure the use of food to encourage/discourage child behaviour. Five items are specified as 'other' so that the parents can fill in specific scenarios that might not be addressed in the questionnaire. There are also two more questions inviting parents to share more information about the use of food to soothe and the use of food to encourage or discourage behaviours. ${ }^{87}$ The scales were retrieved by personal communication with the author ${ }^{164}$ and translated into French using standard techniques. ${ }^{163}$

Parental response to hunger/satiety clues is assessed with the Infant Feeding Style Questionnaire: Satiety subscale, ${ }^{165}$ designed to assess parental feeding practices. This parent-report measure consists of five subscales that tap parental control practices and attitudes in child feeding. ${ }^{87}$ In this study, we use the satiety subscale. Two of the items probe beliefs and are coded on a 5-point Likert scale ranging from 1 'disagree' to 5 'agree'. The five other items probe behaviours and are coded on a 5-point Likert scale ranging from 1 'never' to 5 'always'. The scales were obtained directly from the author ${ }^{166}$ and translated into French using standard techniques. ${ }^{163}$

\section{Self-report questionnaires: offspring}

Offspring sleep duration and quality are measured with the BISQ. ${ }^{167}$ The role of the responder is asked as well as the age, gender and birth order of the child. The parent rates their child's nocturnal sleep duration, daytime sleep duration, number of night waking, 
duration of wakefulness during the night hours, nocturnal sleep-onset time, settling time, method of falling asleep, location of sleep and preferred body position during the past week. It has 14 items, which all have specific scoring measures related to the type of question. BISQ scores correlate significantly with sleep measures derived from actigraphy and sleep diaries. ${ }^{167}$ The scales were obtained directly from the author ${ }^{168}$ and translated into French using standard techniques. ${ }^{163}$

Offspring self-regulation is assessed with the PSI-SF ${ }^{158}$ (see above).

\section{Physical activity and fitness measures}

Physical activity (total physical activity and its intensity) is assessed using an accelerometer (GeneActiv) that is worn on the right wrist during 10 consecutive days. ${ }^{169}$

The Chester Step Test, a multistage submaximal exercise test, is performed to estimate aerobic fitness (maximal oxygen uptake $\left.\left(\mathrm{V}^{\prime} \mathrm{O}_{2 \max }\right)\right) \cdot{ }^{170}$ Before starting the test, patients are instructed and experience a $30 \mathrm{~s}$ familiarisation. During the test, the step rate (assessed by an audiotape) starts at $15 \mathrm{step} / \mathrm{min}$ and increases of $5 \mathrm{step} / \mathrm{min}$ every $2 \mathrm{~min}$. Patients are asked to step up and down for a maximum of $10 \mathrm{~min}$. Step height $(15,20$ or $25 \mathrm{~cm})$ can be adapted depending on the physical characteristics and/or activity level of the patients. Heart rate (HR) and rate of perceived exertion (RPE) on Borg's scale are monitored at the end of each 2 min stage. The test is stopped when patients reach $80 \%$ of the estimated $\mathrm{HR}_{\max }$ (220-age), when $\mathrm{RPE} \geq 15$ or when the patient shows signs of distress during the test. The $\mathrm{VO}_{2 \max }$ is then estimated using a standardised equation. The Chester step-test was validated against indirect calorimetry and demonstrated reasonable validity. ${ }^{171}$

Muscular fitness is assessed with a hand grip strength dynamometer (Jamar dynamometer) following standard procedure. ${ }^{172}$ Before starting the test, patients are instructed on the correct use of the dynamometer (hand and wrist position during squeezing). Then, patients are seated in a chair and are asked to squeeze the dynamometer as tightly as possible. A verbal encouragement is given during the test. Three measures are taken for each hand and the highest value is considered for analysis.

\section{Physical examination: body composition assessments}

Weight is measured in mothers, fathers as well as their babies to the closest $100 \mathrm{~g}$. For the mothers and fathers, a calibrated scale (Seca model 220) is used. Participants are asked to remove their shoes as well as any heavy clothing (jeans, jacket, scarf and so on). For babies, a calibrated scale (model Seca 336) is used and they are weighed without any clothes or nappy.

Height is measured in mothers, fathers as well as length in babies to the closest $\mathrm{mm}$. For the mothers and fathers, a calibrated scale (Seca model 220) is used and they are asked to remove their shoes. For babies, a calibrated scale (Seca model 336) is used. The infant's head is placed against the head positioner (Seca model 419), then the experimenter lightly presses on the infant's knees and measures the infant's length with the measuring rod (Seca model 232).

Total fat mass of the mother and her offspring are measured with BIA and skinfolds. BIA measures the reactance and the resistance of the patient. ${ }^{173}$ Any metallic objects such as watches, bracelets or others are removed before starting the BIA. The participant needs to lie down, arms and legs spread away from each other, so that there is no contact between the limbs. Four electrodes are positioned; two on the right hand and two on the right foot, at a distance of 3-4 cm from each other (BIA 101, Akern, Italy). Obese women with an altered body composition can be identified and monitored using vector BIA. ${ }^{174}$ A relaxation phase of $10 \mathrm{~min}$ is respected before measurements are taken. Skinfolds are measured with a Harpenden skinfold calliper (HSK-BI, British Indicators, UK) on the biceps, the triceps, the subscapular and the iliac crest. Muscle tissues are not included in the skinfolds. Measures for the mothers are taken on the right side of the body while standing up. Measurements are taken twice, and a third time if the difference between the two first measures is over $1 \mathrm{~mm}$. A mean between the two or three values is calculated. ${ }^{175}{ }^{176}$ For the babies, the measures are taken once on the left hand side while their mothers are holding them. ${ }^{177}$

Total and regional fat mass measured by Dual-Energy X-ray absorptiometry (mother). Participants are asked to remove all metal items before densitometry and are examined while wearing only their underwear and a cloth gown. The subjects are placed in a supine position with their arms at their sides but held slightly separated from their trunk and correctly centred on the scanning field. Regions of interest are defined by the analytical programme, and include different corporeal districts: total body, trunk, head, pelvic, upper limbs, lower limbs, android and gynoid region. For each region, DXA scans bone mineral content, bone areal size and weight (in grams) of total mass, FM and non-bone lean mass. For the android and gynoid regions, the ratio between android and gynoid fat distribution is also assessed. Also calculated are a FM index $\left(\mathrm{kg} / \mathrm{m}^{2}\right)$, computed as the ratio of total body FM over height squared and a skeletal muscle mass index $\left(\mathrm{kg} / \mathrm{m}^{2}\right)$, computed as the ratio of appendicular skeletal muscle mass over height squared. Finally, the intravisceral fat index is assessed using a special algorithm provided by the manufacturer.

Blood pressure in mothers and their partners is measured by obtaining three readings at 2 min intervals with a clinically validated oscillometric sphygmomanometer (OMRON HEM-907, Japan). 


\section{Laboratory variables \\ Mother}

Cardiometabolic laboratory variables such as HbA1c, lipid levels, gamma-GT, B12 vitamin, ferritin will be measured at study beginning, at 6-8 weeks and at 1 year postpartum and miRNA will be additionally also measured at birth. At 6-8 weeks and at 1 year postpartum, a $75 \mathrm{~g}$ oGTT with blood sampling at 30 min intervals for 2 hour will be performed to assess glucose tolerance and indices of insulin secretion and sensitivity.

\section{Offspring}

Cord blood sample will be obtained at the time of birth to measure lipid levels, glucose, HbAlc and other cardiometabolic laboratory parameters as well as miRNA (for more details, see Di Bernardo et $a l^{142}$ ). A sample of the respective blood draw will be kept for future potential analyses.

\section{Sample size calculation}

Sample size was computed based on the expected difference in primary outcomes between the control and the intervention group. The weight assumptions are based on our pilot data and goals for weight retention. Regarding maternal weight, we assumed a weight reduction of $8.4 \mathrm{~kg}$ (SD: 5.5 ) between study enrolment at 24-32 GA, after GDM diagnosis and 1 year postpartum in women allocated to the control group compared with a weight reduction of $10.9 \mathrm{~kg}$ (SD: 5.5) in women allocated to the intervention group. The required sample size is 76 women in each study group to have a statistical significant difference with a power of $80 \%$ and an alpha-level set at 0.05 (two-sided).

This sample size is also sufficient to observe statistical significant differences in the reduction in the Edinburgh Postnatal Depression symptoms score, if we assume that the reduction in depression symptoms score between the above-mentioned two time points is 0.2 (SD: 4.3) in women allocated to the control group and 2.2 (SD: 4.4) in women allocated to the intervention group. Assuming a maximum attrition rate of $30 \%$, we will include 100 women in the control and 100 in the intervention groups to provide adequate power.

\section{STATISTICAL ANALYSIS}

For the primary aim, differences in the changes in maternal weight and the EPDS symptoms score between enrolment after GDM diagnosis and 1 year postpartum at the end of the study between the intervention and the control group will be analysed using linear regression analysis. For the secondary aims, the analyses will be performed both for differences in changes between the intervention and the control group and for differences between groups at different time points (baseline at inclusion, childbirth, 6-8 weeks and 1 year postpartum) in maternal metabolic health outcomes, maternal mental health outcomes and offspring metabolic and mental health outcomes. This will be tested using linear regression analysis. We will compare the proportion of patients meeting guidelines for gestational weight gain and for weight retention at 1 year postpartum between the two groups using logistic regression analyses. Associations between outcomes will be tested using linear regression analyses.

Differences between groups will be adjusted for the respective baseline values in case they differ. Variables will be transformed if residuals are not normally distributed. We will include potential confounding variables, if necessary. These include maternal age, sex of the children, the presence of prenatal, perinatal and early postnatal conditions/complications, BMI, EPDS symptoms score and socioeconomic status where applicable. Subgroup analyses will be performed according to weight status, mental health status (EPDS score $<10$ vs $\geq 10$ ), prediabetes status at the initial postpartum evaluation (6-8 weeks postpartum) as well as sex (for the children). Analyses will be conducted with STATA V.14.0. For confirmatory analyses, a Bonferroni correction for multiple analyses will be applied. For initial exploratory analyses, no such correction will be used. ${ }^{178}$ For the partners, we will evaluate changes between groups and differences between groups at different time points (baseline at inclusion, 1 year postpartum) in weight and paternal eating behaviour and mental health outcomes.

Finally, a process evaluation nested inside the trial will be conducted in order to assess fidelity and quality of implementation, to clarify causal mechanisms and to identify contextual factors associated with variation in outcomes. $^{179}$

\section{ADVERSE EVENTS}

All expected and unexpected adverse events will be recorded during the entire study period. A recognised potential risk is the occurrence of early contractions due to intense physical activity. In order to monitor and mitigate this potential risk, patients will be closely supervised by a physician and a physiotherapist. In case of early contractions, participants will be requested to reduce or stop their physical activity.

\section{DATA MANAGEMENT}

All study data will be entered by research staff (PhD students and study co-ordinator). All data will be precoded and stored in a secured database (Secutrial), which will be regularly updated by the IT Service of the Lausanne University Hospital. Double data entry will be done for the primary outcomes. For the rest of the data, a random $5 \%$ will be double-checked. 


\section{MONITORING}

Monitoring will be performed by a qualified person independent of the study group and will be organised in two parts: the initial visit took place before the start of recruitment and the second visit after approximately $10 \%$ of the study population have been recruited.

\section{ETHICS AND DISSEMINATION}

The trial poses little to no risk to participants and their offspring. Signed informed consent is obtained from all participating women. Participation in the study does not interfere with the typical care patients receive during pregnancy and after childbirth. Results from this study will be disseminated at regional and international conferences and in peer-reviewed journals. The MySweetHeart Trial is a registered trial (clinicaltrials.gov/ct2/show/NCT02890693) and linked to the MySweetHeart Cohort (clinicaltrials.gov/ct2/show/ NCT02872974).

\section{SIGNIFICANCE AND OUTLOOK}

This project will provide relevant findings regarding understanding of GDM, potential pathways and its link to lifestyle, mental health and the development and trajectories of obesity and diabetes in the mothers and obesity in their offspring. It will also provide relevant findings regarding treatment of GDM and its impact on complications such as diabetes and obesity and may thus help to elucidate potential solutions, thus leading to significant changes in clinical practice and guidelines.

Due to its interdisciplinary nature, this research is of interest for clinicians, educators and researchers in the field of diabetes, obstetrics, paediatrics and development, psychology, sport and nutrition sciences and public health.

\section{Author affiliations}

${ }^{1}$ Woman-Mother-Child Department, Lausanne University Hospital, Lausanne, Switzerland

${ }^{2}$ Institute of Higher Education and Research in Healthcare (IUFRS), University of Lausanne, Lausanne, Switzerland

${ }^{3}$ Service of Endocrinology, Diabetes and Metabolism, Lausanne University Hospital, Lausanne, Switzerland

${ }^{4}$ Service of Angiology, Heart and Vessel Department, Lausanne University Hospital, Lausanne, Switzerland

${ }^{5}$ Institute of Sport Sciences, University of Lausanne, Lausanne, Switzerland ${ }^{6}$ DOHad Laboratory, Pediatrics Division, Woman-Mother-Child Department, Lausanne University Hospital, Lausanne, Switzerland

${ }^{7}$ Center of Bone Diseases, Rheumatology Service, Bone and Joint Department, Lausanne University Hospital, Lausanne, Switzerland

${ }^{8}$ Consultation Liaison Psychiatry, Lausanne University Hospital, Lausanne, Switzerland

${ }^{9}$ Applied Social and Health Psychology, Department of Psychology, University Research Priority Program Dynamics of Healthy Aging, University of Zurich, Lausanne, Switzerland

${ }^{10}$ Facultad de Ciencias de la Actividad Física y del Deporte-INEF, Universidad Politécnica de Madrid, Madrid, Spain
${ }^{11}$ Service of Pediatric Endocrinology, Diabetology and Obesity, Lausanne University Hospital, Lausanne, Switzerland

Acknowledgements We would like to thank Dominique Stulz, Céline Helbling, Véronique Pidoux, Giada 0stinelli, Chloé Beutler and Agnes Bacso for their help with administration and data collection. We are grateful to Olivier Le Dizes, Magali Andrey, Andrea Orechio, Laura Marino, Antonella Corcillo, Carine Mekoguem, Christophe Kosinski, Sylvie Girardin, Stephanie Roudet, for delivering the usual care condition and to Nelly Pitteloud and Jean-François Tolsa for departmental support.

Collaborators The following are members of MySweetheart Research Group (including the authors of the present article), listed in alphabetical order: Ruben Barakat, PhD, Professor (Facultad de Ciencias de la Actividad Física y del DeporteINEF, Universidad Politécnica de Madrid, Madrid, Spain; barakatruben@gmail. com), Alexandre Berney, MD, Professor (Consultation Liaison Psychiatry, Lausanne University Hospital, Lausanne, Switzerland; alexander.berney@chuv.ch), Pascal Bovet, MD MPH, Professor (Institute of Social and Preventive Medicine (IUMSP), Lausanne University Hospital, Lausanne, Switzerland; pascal.bovet@chuv.ch), Jenni Brand-Miller, AM, FAIFST, FNSA, Professor (School of Life and Environmental Sciences and Charles Perkins Centre, University of Sydney, Australia; jennie. brandmiller@sydney.edu.au); Arnaud Chiolero, MD PhD, Senior lecturer (Institute of Social and Preventive Medicine (IUMSP), Lausanne University Hospital, Lausanne, Switzerland; Department of Epidemiology, Biostatistics, and Occupational Health, McGill University, Montreal Canada; Institute of Primary Health Care (BIHAM), University of Bern, Switzerland; arnaud.chiolero@chuv.ch), Stefano Di Bernardo, MD, Lecturer (Pediatric Cardiology Unit, Woman-Mother-Child Department, Lausanne University Hospital, Lausanne, Switzerland; stefano.di-bernardo@chuv. ch), Adina Epure, MD (Pediatric Cardiology Unit, Woman-Mother-Child Department; Institute of Social and Preventive Medicine (IUMSP), Lausanne University Hospital, Lausanne, Switzerland; adina-mihaela.epure@chuv.ch), Sandrine Estoppey, M.Sc. (Institute of Social and Preventive Medicine (IUMSP), Lausanne University Hospital, Lausanne, Switzerland; sandrine.estoppey@chuv.ch), Leah Gilbert, M.Sc. (Service of Endocrinology, Diabetes and Metabolism, Department of Medicine, Lausanne University Hospital, Lausanne, Switzerland; leah.gilbert@chuv.ch), Elena GonzalezRodriguez, MD (Service of Endocrinology, Diabetes and Metabolism, Department of Medicine, Lausanne University Hospital, Lausanne, Switzerland; elena-gonzalez@ chuv.ch), Justine Gross, HES (Service of Endocrinology, Diabetes and Metabolism, Department of Medicine, Lausanne University Hospital, Lausanne, Switzerland; justine.gross@chuv.ch), Didier Hans, MD (Center of Bone Diseases, Rheumatology Service, Bone \& Joint Department, Lausanne University Hospital, Lausanne, Switzerland; didier.hans@chuv.ch), Antje Horsch, DClinPsych, Professor (Institute of Higher Education and Research in Healthcare (IUFRS), University of Lausanne and Woman-Mother-Child Department, Lausanne University Hospital, Lausanne, Switzerland; antje.horsch@chuv.ch), Bengt Kayser, MD, PhD, Professor (Institute of Sport Sciences, University of Lausanne; bengt.kayser@unil.ch), Stefano Lanzi, PhD (Service of Endocrinology, Diabetes and Metabolism, Department of Medicine and Service of Angiology, Heart and Vessel Department, Lausanne University Hospital, Lausanne, Switzerland; stefano.lanzi@chuv.ch), Yvan Mivelaz, MD, Lecturer (Pediatric Cardiology Unit, Woman-Mother-Child Department, Lausanne University Hospital, Lausanne, Switzerland; yvan.mivelaz@chuv.ch), Jardena J Puder, MD, Professor (Service of Endocrinology, Diabetes and Metabolism, Department of Medicine and Service of Pediatric Endocrinology, Diabetology and Obesity, Lausanne University Hospital, Lausanne, Switzerland; jardena.puder@chuv.ch), Dan Quansah, MPH (Service of Endocrinology, Diabetes and Metabolism, Department of Medicine, Lausanne University Hospital, Lausanne, Switzerland), Urte Scholz, PhD, Professor (Applied Social and Health Psychology, Department of Psychology \& University Research Priority Program Dynamics of Healthy Aging, University of Zurich, Zurich, Switzerland; urte.scholz@psychologie.uzh.ch), Nicole Sekarski, MD, Professor (Pediatric Cardiology Unit, Woman-Mother-Child Department, Lausanne University Hospital, Lausanne, Switzerland; nicole.sekarski@chuv.ch), Umberto Simeoni, MD, Professor (DOHad Laboratory, Pediatrics Division, Woman-MotherChild Department, Lausanne University Hospital, Lausanne, Switzerland; umberto. simeoni@chuv.ch), Benazir Siddeek, Ph.D. (DOHad Laboratory, Pediatrics Division, Woman-Mother-Child Department, Lausanne University Hospital, Lausanne, Switzerland; benazir.siddeek@chuv.ch), Yvan Vial, MD, Professor (Obstetrics and Gynecology Division, Woman-Mother-Child Department, Lausanne University Hospital, Lausanne, Switzerland; yvan.vial@chuv.ch).

Contributors JJP and AH designed the study with input from all other authors. $\mathrm{AH}$ and JJP drafted the manuscript and contributed equally to the present work. LG, SL, $\mathrm{JG}, \mathrm{BK}, \mathrm{YV}, \mathrm{USi}, \mathrm{DH}, \mathrm{AB}, \mathrm{USC}$ and RB significantly contributed to the establishment and refinement of study procedures and critically revised the manuscript. All authors approved the final version of the manuscript. 
Funding This study is funded by a project grant by the Swiss National Science Foundation (SNF 32003B_176119).

Competing interests None declared.

Patient consent Obtained.

Ethics approval Ethical approval was granted by the Human Research Ethics Committee of the Canton de Vaud (study number 2016-00745).

Provenance and peer review Not commissioned; peer reviewed for ethical and funding approval prior to submission.

Data sharing statement Individual participant data collected during the trial (after deidentification) that underlie the publications from MySweetHeart research group will be available on reasonable request.

Open Access This is an Open Access article distributed in accordance with the Creative Commons Attribution Non Commercial (CC BY-NC 4.0) license, which permits others to distribute, remix, adapt, build upon this work non-commercially, and license their derivative works on different terms, provided the original work is properly cited and the use is non-commercial. See: http://creativecommons.org/ licenses/by-nc/4.0/

(c) Article author(s) (or their employer(s) unless otherwise stated in the text of the article) 2018. All rights reserved. No commercial use is permitted unless otherwise expressly granted.

\section{REFERENCES}

1. Blumer I, Hadar E, Hadden DR, et al. Diabetes and pregnancy: an endocrine society clinical practice guideline. J Clin Endocrinol Metab 2013;98:4227-49.

2. Association AD. Standards of medical care in diabetes-2017: Summary of revisions. Diabetes Care 2017;40:S4-s5.

3. Benhalima K, Jegers K, Devlieger R, et al. Glucose intolerance after a recent history of gestational diabetes based on the 2013 who criteria. PLoS One 2016;11:e0157272.

4. Ryser Rüetschi J, Jornayvaz FR, Rivest R, et al. Fasting glycaemia to simplify screening for gestational diabetes. BJOG 2016;123:2219-22.

5. Bellamy L, Casas JP, Hingorani AD, et al. Type 2 diabetes mellitus after gestational diabetes: a systematic review and meta-analysis. Lancet 2009;373:1773-9.

6. Lauenborg J, Hansen T, Jensen DM, et al. Increasing incidence of diabetes after gestational diabetes: a long-term follow-up in a Danish population. Diabetes Care 2004;27:1194-9.

7. Retnakaran R, Shah BR. Mild glucose intolerance in pregnancy and risk of cardiovascular disease: a population-based cohort study. CMAJ 2009;181:371-6.

8. Harreiter J, Dovjak G, Kautzky-Willer A. Gestational diabetes mellitus and cardiovascular risk after pregnancy. Womens Health 2014;10:91-108.

9. Hinkle SN, Buck Louis GM, Rawal S, et al. A longitudinal study of depression and gestational diabetes in pregnancy and the postpartum period. Diabetologia 2016;59:2594-602.

10. Nicklas JM, Miller LJ, Zera CA, et al. Factors associated with depressive symptoms in the early postpartum period among women with recent gestational diabetes mellitus. Matern Child Health J 2013;17:1665-72.

11. Staiano AE, Marker AM, Martin CK, et al. Physical activity, mental health, and weight gain in a longitudinal observational cohort of nonobese young adults. Obesity 2016;24:1969-75

12. Poston L. Maternal obesity, gestational weight gain and diet as determinants of offspring long term health. Best Pract Res Clin Endocrinol Metab 2012;26:627-39.

13. Hanson MA, Gluckman PD. Early developmental conditioning of later health and disease: physiology or pathophysiology? Physiol Rev 2014;94:1027-76.

14. Simeoni U, Yzydorczyk C, Siddeek B, et al. Epigenetics and neonatal nutrition. Early Hum Dev 2014;90 Suppl 2:S23-S24.

15. Gluckman PD, Hanson MA, Cooper $C$, et al. Effect of in utero and early-life conditions on adult health and disease. N Engl J Med 2008;359:61-73.

16. Nehring I, Chmitorz A, Reulen $\mathrm{H}$, et al. Gestational diabetes predicts the risk of childhood overweight and abdominal circumference independent of maternal obesity. Diabet Med 2013;30:1449-56.

17. Crume TL, Ogden L, West NA, et al. Association of exposure to diabetes in utero with adiposity and fat distribution in a multiethnic population of youth: the Exploring Perinatal Outcomes among Children (EPOCH) Study. Diabetologia 2011;54:87-92.
18. Chandler-Laney PC, Bush NC, Granger WM, et al. Overweight status and intrauterine exposure to gestational diabetes are associated with children's metabolic health. Pediatr Obes 2012;7:44-52.

19. Mehta SH, Kruger M, Sokol RJ. Is maternal diabetes a risk factor for childhood obesity? J Matern Fetal Neonatal Med 2012;25:41-4.

20. Pettitt DJ, McKenna S, McLaughlin C, et al. Maternal glucose at 28 weeks of gestation is not associated with obesity in 2-yearold offspring: the Belfast Hyperglycemia and Adverse Pregnancy Outcome (HAPO) family study. Diabetes Care 2010;33:1219-23.

21. Zhao P, Liu E, Qiao Y, et al. Maternal gestational diabetes and childhood obesity at age 9-11: results of a multinational study. Diabetologia 2016;59:2339-48.

22. Logan KM, Emsley RJ, Jeffries S, et al. Development of early adiposity in infants of mothers with gestational diabetes mellitus. Diabetes Care 2016;39:1045-51.

23. Kc K, Shakya S, Zhang H. Gestational diabetes mellitus and macrosomia: a literature review. Ann Nutr Metab 2015;66 Suppl 2:14-20.

24. Clausen TD, Mathiesen ER, Hansen T, et al. High prevalence of type 2 diabetes and pre-diabetes in adult offspring of women with gestational diabetes mellitus or type 1 diabetes: the role of intrauterine hyperglycemia. Diabetes Care 2008;31:340-6.

25. Dello Russo M, Ahrens W, De Vriendt T, et al. Gestational weight gain and adiposity, fat distribution, metabolic profile, and blood pressure in offspring: the IDEFICS project. Int $J$ Obes 2013;37:914-9.

26. Black $\mathrm{MH}$, Sacks $\mathrm{DA}$, Xiang $\mathrm{AH}$, et al. The relative contribution of prepregnancy overweight and obesity, gestational weight gain, and IADPSG-defined gestational diabetes mellitus to fetal overgrowth. Diabetes Care 2013;36:56-62.

27. Harrod CS, Chasan-Taber L, Reynolds RM, et al. Physical activity in pregnancy and neonatal body composition: the Healthy Start study. Obstet Gynecol 2014;124:257-64.

28. Lovejoy MC, Graczyk PA, O'Hare E, et al. Maternal depression and parenting behavior: a meta-analytic review. Clin Psychol Rev 2000;20:561-92.

29. Carter AS, Garrity-Rokous FE, Chazan-Cohen R, et al. Maternal depression and comorbidity: predicting early parenting, attachment security, and toddler social-emotional problems and competencies. J Am Acad Child Adolesc Psychiatry 2001;40:18-26

30. Hoffman C, Crnic KA, Baker JK. Maternal Depression and Parenting: Implications for Children's Emergent Emotion Regulation and Behavioral Functioning. Parenting 2006;6:271-95.

31. Wake M, Nicholson JM, Hardy P, et al. Preschooler obesity and parenting styles of mothers and fathers: Australian national population study. Pediatrics 2007;120:e1520-e1527.

32. Cosson $\mathrm{E}$, Bihan $\mathrm{H}$, Reach $\mathrm{G}$, et al. Psychosocial deprivation in women with gestational diabetes mellitus is associated with poor fetomaternal prognoses: an observational study. BMJ Open 2015;5:e007120.

33. $\mathrm{Ng} \mathrm{M}$, Fleming $\mathrm{T}$, Robinson $\mathrm{M}$, et al. Global, regional, and national prevalence of overweight and obesity in children and adults during 1980-2013: A systematic analysis for the global burden of disease study 2013. Lancet 2014;384:766-81.

34. Hirst JE, Villar J, Papageorghiou AT, et al. Preventing childhood obesity starts during pregnancy. Lancet 2015;386:1039-40.

35. Koivusalo SB, Rönö K, Klemetti MM, et al. Gestational diabetes mellitus can be prevented by lifestyle intervention: The finnish gestational diabetes prevention study (radiel): A randomized controlled trial. Diabetes Care 2016;39:24-30.

36. Brownfoot FC, Davey MA, Kornman L. Routine weighing to reduce excessive antenatal weight gain: a randomised controlled trial. BJOG 2016;123:254-61.

37. Bao W, Bowers K, Tobias DK, et al. Prepregnancy dietary protein intake, major dietary protein sources, and the risk of gestational diabetes mellitus: a prospective cohort study. Diabetes Care 2013;36:2001-8.

38. Garaulet M, Madrid JA. Chronobiological aspects of nutrition, metabolic syndrome and obesity. Adv Drug Deliv Rev 2010;62:967-78.

39. Pot GK, Almoosawi S, Stephen AM. Meal irregularity and cardiometabolic consequences: results from observational and intervention studies. Proc Nutr Soc 2016;75:475-86.

40. Alhussain MH, Macdonald IA, Taylor MA. Irregular meal-pattern effects on energy expenditure, metabolism, and appetite regulation: a randomized controlled trial in healthy normal-weight women. Am J Clin Nutr 2016;104:21-32.

41. Renault KM, Carlsen EM, Nørgaard K, et al. Intake of sweets, snacks and soft drinks predicts weight gain in obese pregnant 
women: Detailed analysis of the results of a randomised controlled trial. PLoS One 2015;10:e0133041.

42. Fuglestad PT, Jeffery RW, Sherwood NE. Lifestyle patterns associated with diet, physical activity, body mass index and amount of recent weight loss in a sample of successful weight losers. Int $J$ Behav Nutr Phys Act 2012;9:79.

43. Hosler AS, Nayak SG, Radigan AM. Stressful events, smoking exposure and other maternal risk factors associated with gestational diabetes mellitus. Paediatr Perinat Epidemiol 2011;25:566-74.

44. Spirito A, Ruggiero L, Bowen A, et al. Stress, coping, and social support as mediators of the emotional status of women with gestational diabetes. Psychol Health 1991;5:111-20.

45. Horsch A, Kang JS, Vial Y, et al. Stress exposure and psychological stress responses are related to glucose concentrations during pregnancy. Br J Health Psychol 2016;21:712-29.

46. Giesbrecht GF, Campbell T, Letourneau N, et al. Psychological distress and salivary cortisol covary within persons during pregnancy. Psychoneuroendocrinology 2012;37:270-9.

47. Sauder KA, Starling AP, Shapiro AL, et al. Diet, physical activity and mental health status are associated with dysglycaemia in pregnancy: the Healthy Start Study. Diabet Med 2016;33:663-7.

48. Leppänen M, Aittasalo M, Raitanen J, et al. Physical activity during pregnancy: predictors of change, perceived support and barriers among women at increased risk of gestational diabetes. Matern Child Health J 2014;18:2158-66.

49. Lydon K, Dunne FP, Owens L, et al. Psychological stress associated with diabetes during pregnancy: a pilot study. Ir Med J 2012;105:26-8.

50. Perales M, Refoyo I, Coteron J, et al. Exercise during pregnancy attenuates prenatal depression: a randomized controlled trial. Eval Health Prof 2015;38:59-72.

51. Huang $\mathrm{C}$, Momma $\mathrm{H}, \mathrm{Cui} \mathrm{Y}$, et al. Independent and combined relationship of habitual unhealthy eating behaviors with depressive symptoms: A prospective study. J Epidemiol 2017;27:42-7.

52. Mantzios M, Wilson JC. Making concrete construals mindful: a novel approach for developing mindfulness and self-compassion to assist weight loss. Psychol Health 2014;29:422-41.

53. Mantzios M, Wilson JC. Exploring mindfulness and mindfulness with self-compassion-centered interventions to assist weight loss: Theoretical considerations and preliminary results of a randomized pilot study. Mindfulness 2015;6:824-35.

54. Alberts HJ, Mulkens S, Smeets M, et al. Coping with food cravings. Investigating the potential of a mindfulness-based intervention. Appetite 2010:55:160-3

55. Louie JC, Brand-Miller JC, Markovic TP, et al. Glycemic index and pregnancy: a systematic literature review. J Nutr Metab 2010;2010:1-8.

56. Viana LV, Gross JL, Azevedo MJ. Dietary intervention in patients with gestational diabetes mellitus: a systematic review and metaanalysis of randomized clinical trials on maternal and newborn outcomes. Diabetes Care 2014;37:3345-55.

57. Wei J, Heng W, Gao J. Effects of low glycemic index diets on gestational diabetes mellitus: A meta-analysis of randomized controlled clinical trials. Medicine 2016;95:e3792.

58. Han S, Middleton P, Shepherd E, et al. Different types of dietary advice for women with gestational diabetes mellitus. Cochrane Database Syst Rev 2017;2:Cd009275.

59. Bowers K, Tobias DK, Yeung E, et al. A prospective study of prepregnancy dietary fat intake and risk of gestational diabetes. Am J Clin Nutr 2012:95:446-53.

60. Risérus U, Willett WC, Hu FB. Dietary fats and prevention of type 2 diabetes. Prog Lipid Res 2009;48:44-51.

61. Schoenaker DA, Mishra GD, Callaway LK, et al. The role of energy, nutrients, foods, and dietary patterns in the development of gestational diabetes mellitus: A systematic review of observational studies. Diabetes Care 2016;39:16-23.

62. Bao W, Li S, Chavarro JE, et al. Low carbohydrate-diet scores and long-term risk of type 2 diabetes among women with a history of gestational diabetes mellitus: A prospective cohort study. Diabetes Care 2016;39:43-9.

63. Hernandez TL, Van Pelt RE, Anderson MA, et al. Women with gestational diabetes mellitus randomized to a higher-complex carbohydrate/low-fat diet manifest lower adipose tissue insulin resistance, inflammation, glucose, and free fatty acids: A pilot study. Diabetes Care 2016;39:39-42

64. Youngwanichsetha S, Phumdoung S, Ingkathawornwong T. The effects of mindfulness eating and yoga exercise on blood sugar levels of pregnant women with gestational diabetes mellitus. Appl Nurs Res 2014;27:227-30.
65. Mason AE, Epel ES, Kristeller J, et al. Effects of a mindfulnessbased intervention on mindful eating, sweets consumption, and fasting glucose levels in obese adults: data from the SHINE randomized controlled trial. J Behav Med 2016;39:201-13.

66. Anon. ACog committee opinion no. 650: Physical activity and exercise during pregnancy and the postpartum period. Obstet Gynecol 2015;126:e135-42.

67. Colberg SR, Sigal RJ, Yardley JE, et al. Physical activity/exercise and diabetes: A position statement of the american diabetes association. Diabetes Care 2016;39:2065-79.

68. Colberg SR, Castorino K, Jovanovič L. Prescribing physical activity to prevent and manage gestational diabetes. World J Diabetes 2013;4:256-62.

69. Melzer K, Schutz Y, Boulvain M, et al. Physical activity and pregnancy. Sports Medicine 2010;40:493-507.

70. Ruchat SM, Mottola MF. The important role of physical activity in the prevention and management of gestational diabetes mellitus. Diabetes Metab Res Rev 2013;29:334-46.

71. May LE, Scholtz SA, Suminski R, et al. Aerobic exercise during pregnancy influences infant heart rate variability at one month of age. Early Hum Dev 2014;90:33-8.

72. Horsch A, Gross J, Jornayvaz FR, et al. [Gestational diabeteswhat are the non-medical approaches?]. Rev Med Suisse 2016;12:1089-91.

73. Brazeau AS, Leong A, Meltzer SJ, et al. Group-based activities with on-site childcare and online support improve glucose tolerance in women within 5 years of gestational diabetes pregnancy. Cardiovasc Diabetol 2014;13:104.

74. Dasgupta K, Da Costa D, Pillay S, et al. Strategies to optimize participation in diabetes prevention programs following gestational diabetes: a focus group study. PLoS One 2013;8:e67878.

75. Brown HL. Acog guidelines at a glance: Gestational diabetes mellitus. Obstetrics and gynecology 2013;122:406-16.

76. Gabbe SG, Landon MB, Warren-Boulton E, et al. Promoting health after gestational diabetes: A national diabetes education program call to action. Obstet Gynecol 2012;119:171.

77. Sattar N, Wannamethee SG, Forouhi NG. Novel biochemical risk factors for type 2 diabetes: pathogenic insights or prediction possibilities? Diabetologia 2008;51:926-40.

78. Tobias DK, Hu FB, Chavarro J, et al. Healthful dietary patterns and type 2 diabetes mellitus risk among women with a history of gestational diabetes mellitus. Arch Intern Med 2012;172:1566-72.

79. Ferrara A, Hedderson MM, Albright CL, et al. A pregnancy and postpartum lifestyle intervention in women with gestational diabetes mellitus reduces diabetes risk factors: a feasibility randomized control trial. Diabetes Care 2011;34:1519-25.

80. Ferrara A, Hedderson MM, Albright CL, et al. A pragmatic cluster randomized clinical trial of diabetes prevention strategies for women with gestational diabetes: design and rationale of the Gestational Diabetes' Effects on Moms (GEM) study. BMC Pregnancy Childbirth 2014;14:21.

81. Kaiser B, Jeannot E, Razurel C. Determinants of health behaviors after gestational diabetes mellitus: A prospective cohort study in geneva. J Midwifery Womens Health 2016:571-7.

82. Koh D, Miller YD, Marshall AL, et al. Health-enhancing physical activity behaviour and related factors in postpartum women with recent gestational diabetes mellitus. J Sci Med Sport 2010;13:42-5

83. Woo Baidal JA, Locks LM, Cheng ER, et al. Risk factors for childhood obesity in the first 1,000 days: A systematic review. Am J Prev Med 2016;50:761-79.

84. Birch LL, Anzman-Frasca S, Paul IM. Starting early: obesity prevention during infancy. Nestle Nutr Inst Workshop Ser 2012;73:81-94.

85. Paul IM, Bartok CJ, Downs DS, et al. Opportunities for the primary prevention of obesity during infancy. Adv Pediatr 2009;56:107-33.

86. Redsell SA, Edmonds B, Swift JA, et al. Systematic review of randomised controlled trials of interventions that aim to reduce the risk, either directly or indirectly, of overweight and obesity in infancy and early childhood. Matern Child Nutr 2016;12:24-38.

87. Stifter CA, Anzman-Frasca S, Birch LL, et al. Parent use of food to soothe infant/toddler distress and child weight status. An exploratory study. Appetite 2011;57:693-9.

88. Wardle J, Sanderson S, Guthrie CA, et al. Parental feeding style and the inter-generational transmission of obesity risk. Obes Res 2002;10:453-62.

89. Reilly JJ, Armstrong J, Dorosty AR, et al. Early life risk factors for obesity in childhood: cohort study. BMJ 2005;330:1357.

90. Wen LM, Baur LA, Rissel C, et al. Correlates of body mass index and overweight and obesity of children aged 2 years: findings from the healthy beginnings trial. Obesity 2014;22:1723-30. 
91. de Vries AG, Huiting HG, van den Heuvel ER, et al. An activity stimulation programme during a child's first year reduces some indicators of adiposity at the age of two-and-a-half. Acta Paediatr 2015;104:414-21.

92. Paul IM, Williams JS, Anzman-Frasca S, et al. The Intervention Nurses Start Infants Growing on Healthy Trajectories (INSIGHT) study. BMC Pediatr 2014;14:184.

93. French GM, Nicholson L, Skybo T, et al. An evaluation of mothercentered anticipatory guidance to reduce obesogenic infant feeding behaviors. Pediatrics 2012;130:e507-517.

94. Schwarzer R. Modeling Health Behavior Change: How to Predict and Modify the Adoption and Maintenance of Health Behaviors. Appl Psychol 2008;57:1-29.

95. Berli C, Stadler G, Inauen J, et al. Action control in dyads: A randomized controlled trial to promote physical activity in everyday life. Soc Sci Med 2016;163:89-97.

96. Leventhal $H$, Singer R, Jones S. EFFECTS OF FEAR AND SPECIFICITY OF RECOMMENDATION UPON ATTITUDES AND BEHAVIOR. J Pers Soc Psychol 1965;2:20-9.

97. Gollwitzer PM. Implementation intentions: Strong effects of simple plans. Am Psychol 1999;54:493-503.

98. Gollwitzer PM, Sheeran P. Implementation intentions and goal achievement: A meta-analysis of effects and processes. Adv Exp Soc Psychol 2006;38:69-119.

99. Hagger MS, Luszczynska A. Implementation intention and action planning interventions in health contexts: state of the research and proposals for the way forward. Appl Psychol Health Well Being 2014;6:1-47.

100. Hagger MS, Luszczynska A, de Wit J, et al. Implementation intention and planning interventions in Health Psychology: Recommendations from the Synergy Expert Group for research and practice. Psychol Health 2016;31:814-39.

101. Sniehotta FF, Scholz U, Schwarzer R. Action plans and coping plans for physical exercise: A longitudinal intervention study in cardiac rehabilitation. Br J Health Psychol 2006;11:23-37.

102. Kwasnicka D, Presseau J, White M, et al. Does planning how to cope with anticipated barriers facilitate health-related behaviour change? A systematic review. Health Psychol Rev 2013;7:129-45.

103. Seshiah V, Balaji V. Primordial prevention: maternal health and diabetes. Diabetes Manag 2013;3:333-41.

104. Halperin IJ, Feig DS. The role of lifestyle interventions in the prevention of gestational diabetes. Curr Diab Rep 2014;14:452.

105. Craig P, Dieppe P, Macintyre S, et al. Developing and evaluating complex interventions: the new Medical Research Council guidance. Int J Nurs Stud 2013;50:587-92.

106. Metzger BE, Gabbe SG, Persson B, et al. International Association of Diabetes and Pregnancy Study Groups Recommendations on the Diagnosis and Classification of Hyperglycemia in Pregnancy: Response to Weinert. Diabetes Care 2010;33:e98-82.

107. Nolan CJ. Controversies in gestational diabetes. Best Pract Res Clin Obstet Gynaecol 2011;25:37-49.

108. Crowther CA, Hiller JE, Moss JR, et al. Effect of treatment of gestational diabetes mellitus on pregnancy outcomes. $\mathrm{N} \mathrm{Engl} \mathrm{J}$ Med 2005;352:2477-86.

109. Sox HC, Greenfield S. Comparative effectiveness research: a report from the Institute of Medicine. Ann Intern Med 2009;151:203-5.

110. Yaktine AL, Rasmussen KM. Weight gain during pregnancy: reexamining the guidelines. Washington (DC): National Academies Press, 2009.

111. Carroll DG, Kelley KW. Review of metformin and glyburide in the management of gestational diabetes. Pharm Pract 2014;12:528.

112. Ferrer RL, Carrasco AV. Capability and clinical success. Ann Fam Med 2010;8:454-60.

113. Daniels LA, Mallan KM, Nicholson JM, et al. Outcomes of an early feeding practices intervention to prevent childhood obesity. Pediatrics 2013;132:e109-118.

114. Farrow C, Blissett J. Does maternal control during feeding moderate early infant weight gain? Pediatrics 2006;118:e293-e298.

115. Gunderson EP, Hurston SR, Ning X, et al. Lactation and Progression to Type 2 Diabetes Mellitus After Gestational Diabetes Mellitus: A Prospective Cohort Study. Ann Intern Med 2015;163:889-98.

116. Herring SJ, Rich-Edwards JW, Oken E, et al. Association of postpartum depression with weight retention 1 year after childbirth. Obesity 2008;16:1296-301.

117. Hori H, Teraishi T, Sasayama D, et al. Relationship of temperament and character with cortisol reactivity to the combined dexamethasone/CRH test in depressed outpatients. J Affect Disord 2013;147:128-36.

118. Iglowstein I, Jenni OG, Molinari L, et al. Sleep duration from infancy to adolescence: reference values and generational trends. Pediatrics 2003;111:302-7.
119. Mallan KM, Daniels LA, Wilson JL, et al. Association between maternal depressive symptoms in the early post-natal period and responsiveness in feeding at child age 2 years. Matern Child Nutr 2015;11:926-35.

120. Mallan KM, Sullivan SE, de Jersey SJ, et al. The relationship between maternal feeding beliefs and practices and perceptions of infant eating behaviours at 4 months. Appetite 2016;105:1-7.

121. Paul IM, Savage JS, Anzman SL, et al. Preventing obesity during infancy: a pilot study. Obesity 2011;19:353-61.

122. Redsell SA, Weng S, Swift JA, et al. Validation, Optimal Threshold Determination, and Clinical Utility of the Infant Risk of Overweight Checklist for Early Prevention of Child Overweight. Child Obes 2016;12:202-9.

123. Taveras EM, Blackburn K, Gillman MW, et al. First steps for mommy and me: a pilot intervention to improve nutrition and physical activity behaviors of postpartum mothers and their infants. Matern Child Health J 2011;15:1217-27.

124. Zarrinpar A, Chaix A, Panda S. Daily Eating Patterns and Their Impact on Health and Disease. Trends Endocrinol Metab 2016;27:69-83.

125. SSN. Swiss Society for Nutrition. Nutritional recommendations for Germany, Autria and Switzerland (DACH): Les valeurs de référence DACH pour les apports nutritionnels. 2ème édn, 2015.

126. Ansermet O, Aebi A. Influence des protéines et des lipides chez le diabétique de type 1. Genève, Switzerland: Haute école de santé, 2016.

127. Ley SH, Hamdy O, Mohan V, et al. Prevention and management of type 2 diabetes: dietary components and nutritional strategies. Lancet 2014;383:1999-2007.

128. Marathe PH, Gao HX, Close KL. American Diabetes Association Standards of Medical Care in Diabetes 2017. J Diabetes 2017;9:320-4.

129. Mantzios M, Wilson JC. Mindfulness, Eating Behaviours, and Obesity: A Review and Reflection on Current Findings. Curr Obes Rep 2015;4:141-6.

130. Mathieu J. What should you know about mindful and intuitive eating? J Am Diet Assoc 2009;109:1982-7.

131. Medina WL, Wilson D, de Salvo V, et al. Effects of Mindfulness on Diabetes Mellitus: Rationale and Overview. Curr Diabetes Rev 2017;13:141-7.

132. Barakat R, Lucia A, Ruiz JR. Resistance exercise training during pregnancy and newborn's birth size: a randomised controlled trial. Int J Obes 2009;33:1048-57.

133. Organization WH. Global strategy on diet, physical activity and health: WHO, 2017

134. Healy GN, Dunstan DW, Salmon J, et al. Breaks in sedentary time: beneficial associations with metabolic risk. Diabetes Care 2008;31:661-6.

135. Excellence NIfHaC. Antenatal and postnatal mental health: clinical management and service guidance. London: National Institute for Health and Care Excellence, 2014.

136. Sockol LE. A systematic review of the efficacy of cognitive behavioral therapy for treating and preventing perinatal depression. $J$ Affect Disord 2015;177:7-21.

137. Tremblay MS, Leblanc AG, Carson V, et al. Canadian Physical Activity Guidelines for the Early Years (aged 0-4 years). Appl Physiol Nutr Metab 2012;37:345-56.

138. Michie S, Richardson $M$, Johnston $M$, et al. The behavior change technique taxonomy (v1) of 93 hierarchically clustered techniques: building an international consensus for the reporting of behavior change interventions. Ann Behav Med 2013;46:81-95.

139. Da Costa D, Dritsa M, Larouche J, et al. Psychosocial predictors of labor/delivery complications and infant birth weight: a prospective multivariate study. J Psychosom Obstet Gynaecol 2000;21:137-48.

140. Devsam BU, Bogossian FE, Peacock AS. An interpretive review of women's experiences of gestational diabetes mellitus: proposing a framework to enhance midwifery assessment. Women Birth 2013;26:e69-e76.

141. Wadhwa PD, Entringer S, Buss C, et al. The contribution of maternal stress to preterm birth: issues and considerations. Clin Perinatol 2011;38:351-84.

142. S db, M Y, E A, et al. Assessing the consequences of gestational diabetes mellitus on offspring's cardiovascular health: MySweetHeart Cohort study protocol, Switzerland. BMJ Open in press 2017;7:e016972.

143. Cox JL, Holden JM, Sagovsky R. Detection of postnatal depression. Development of the 10-item Edinburgh Postnatal Depression Scale. Br J Psychiatry 1987;150:782-6.

144. Bunevicius A, Kusminskas L, Pop VJ, et al. Screening for antenatal depression with the Edinburgh Depression Scale. J Psychosom Obstet Gynaecol 2009;30:238-43. 
145. Guedeney N, Fermanian J. Validation study of the French version of the Edinburgh Postnatal Depression Scale (EPDS): new results about use and psychometric properties. Eur Psychiatry 1998;13:83-9.

146. Koch FS, Sepa A, Ludvigsson J. Psychological stress and obesity. $J$ Pediatr 2008;153:839-44.

147. Obel C, Hedegaard M, Henriksen TB, et al. Stress and salivary cortisol during pregnancy. Psychoneuroendocrinology 2005;30:647-56.

148. Jean-Marc T. Plan de codage des variables: questionnaires activité physique (PAFQ) et alimentaires (FFQ), 2009.

149. Theler. Food frequency questionnaire. Switzerland, 2016.

150. Daundasekara SS, Beasley AD, O'Connor DP, et al. Validation of the intuitive Eating Scale for pregnant women. Appetite 2017:112:201-9.

151. Camilleri GM, Méjean C, Bellisle F, et al. Cross-cultural validity of the Intuitive Eating Scale-2. Psychometric evaluation in a sample of the general French population. Appetite 2015;84:34-42.

152. Tylka TL, Kroon Van Diest AM. The Intuitive Eating Scale-2: item refinement and psychometric evaluation with college women and men. J Couns Psychol 2013;60:137-53.

153. Zigmond AS, Snaith RP. The hospital anxiety and depression scale. Acta Psychiatr Scand 1983;67:361-70.

154. Bocéréan C, Dupret E. A validation study of the Hospital Anxiety and Depression Scale (HADS) in a large sample of French employees. BMC Psychiatry 2014;14:1.

155. Herrmann C, Buss U, Snaith R. Hospital Anxiety and Depression Scale-Deutsche Version [Ein Fragebogen von Angst und Depressivität in der somatischen Medizin]. Bern, Schweiz: Hans Huber, 1995.

156. Topp CW, Østergaard SD, Søndergaard S, et al. The WHO-5 Well-Being Index: a systematic review of the literature. Psychother Psychosom 2015;84:167-76.

157. Hochberg G, Pucheu S, Kleinebreil L, et al. WHO-5, a tool focusing on psychological needs in patients with diabetes: the French contribution to the DAWN study. Diabetes Metab 2012;38:515-22.

158. Abidin R, Index PS. Parenting Stress Index (PSI). Odessa, FL: Psychological Assessment Resources:Inc, 1995.

159. Singer LT, Salvator A, Guo S, et al. Maternal psychological distress and parenting stress after the birth of a very low-birth-weight infant JAMA 1999;281:799-805.

160. Smith MT, Wegener ST. Measures of sleep: The Insomnia Severity Index, Medical Outcomes Study (MOS) Sleep Scale, Pittsburgh Sleep Diary (PSD), and Pittsburgh Sleep Quality Index (PSQI). Arthritis \& Rheumatism 2003;49:S184-196.

161. Raphael H. Pittsburgh sleep quality index, 2016.

162. Moser A, Stuck AE, Silliman RA, et al. The eight-item modified Medical Outcomes Study Social Support Survey: psychometric evaluation showed excellent performance. $J$ Clin Epidemiol 2012;65:1107-16

163. Wild D, Grove A, Martin M, et al. Principles of Good Practice for the Translation and Cultural Adaptation Process for Patient-Reported Outcomes (PRO) Measures: report of the ISPOR Task Force for Translation and Cultural Adaptation. Value Health 2005;8:94-104.

164. Stifter C. Food to soothe questionnaire, 2016

165. Thompson AL, Mendez MA, Borja JB, et al. Development and validation of the Infant Feeding Style Questionnaire. Appetite 2009;53:210-21.

166. Thompson A. Infant feeding style questionnaire: satiety subscale, 2016.

167. Sadeh A. A brief screening questionnaire for infant sleep problems: validation and findings for an Internet sample. Pediatrics 2004;113:e570-e577.
168. Sadeh A. Brief infant sleep questionnaire. 2016.

169. Esliger DW, Rowlands AV, Hurst TL, et al. Validation of the GENEA Accelerometer. Med Sci Sports Exerc 2011;43:1085-93.

170. Sykes K, Roberts A. The Chester step test-a simple yet effective tool for the prediction of aerobic capacity. Physiotherapy 2004;90:183-8.

171. Melzer K, Lazzeri M, Armand S, et al. Validation of the Actiheart for estimating physical activity related energy expenditure in pregnancy. Espen J 2012;7:e5-e10.

172. Roberts HC, Denison HJ, Martin HJ, et al. A review of the measurement of grip strength in clinical and epidemiological studies: towards a standardised approach. Age Ageing 2011;40:423-9.

173. Bertrand PC. Marche à suivre pour la mesure de la composition corpoirelle par BIA (Body impedance analyser RJL systemsAKERN). Lausanne, Suisse: CCHU, 2008.

174. Guida B, Trio R, Pecoraro P, et al. Impedance vector distribution by body mass index and conventional bioelectrical impedance analysis in obese women. Nutr Metab Cardiovasc Dis 2003;13:72-9.

175. Knonthropometry ISftao. International standards for anthropometric assessment: International Society for the advancement of Knonthropometry.

176. Durnin JV, Womersley J. Body fat assessed from total body density and its estimation from skinfold thickness: measurements on 481 men and women aged from 16 to 72 years. Br J Nutr 1974;32:77-97.

177. Dauncey MJ, Gandy G, Gairdner D. Assessment of total body fat in infancy from skinfold thickness measurements. Arch Dis Child 1977:52:223-7.

178. Rothman KJ. No adjustments are needed for multiple comparisons. Epidemiology 1990;1:43-6.

179. Oakley A, Strange V, Bonell C, et al. Process evaluation in randomised controlled trials of complex interventions. BMJ 2006;332:413-6.

180. Ferrara A, Hedderson MM, Brown SD, et al. The comparative effectiveness of diabetes prevention strategies to reduce postpartum weight retention in women with gestational diabetes mellitus: The Gestational Diabetes' Effects on Moms (GEM) cluster randomized controlled trial. Diabetes Care 2016;39:65-74.

181. Nishida C. Guideline: sugars intake for adults and children, 2016.

182. Les hydrates de carbone dans I'alimentation: résumés des chapitres. Les hydrates de carbone dans l'alimentation. Berne, Switzerland: Federal Office of Public Health Fsd, 2009.

183. Montonen J, Knekt P, Järvinen R, et al. Whole-grain and fiber intake and the incidence of type 2 diabetes. Am J Clin Nutr 2003;77:622-9.

184. Lake AC M. Breastfeeding: a key to sustainable development. World breastfeeding week Message 2016: Organization UWH, 2016.

185. Swiss Society for Nutrition Nutritional recommendations. L'alimentation du nourrisson durant la première année de vie. Berne: Swiss Society for Nutrition Nutritional recommendations, 2012.

186. Phillips DI, Clark PM, Hales CN, et al. Understanding oral glucose tolerance: comparison of glucose or insulin measurements during the oral glucose tolerance test with specific measurements of insulin resistance and insulin secretion. Diabet Med 1994;11:286-92.

187. Berry JO, Jones WH. The parental stress scale: initial psychometric evidence. J Soc Pers Relat 1995;12:463-72.

188. Abidin RR, Brunner JF. Development of a parenting alliance inventory. J Clin Child Psychol 1995;24:31-40. 